\title{
Impairments of Diabetes Mellitus related Nephropathy and blood bio- chemicals by the Thymus Vulgaris L. and Thymbra Spicata L.
}

\author{
Zafer Akan ${ }^{1}$, Melek Dikilidal ${ }^{2}$, Hulya Ozdemir ${ }^{2}$, Gokhan Oto $^{2}$, Mehmet Bilgehan Yuksel $^{3}$, \\ Salaheddin Akcay ${ }^{4}$, Seda Vatansever ${ }^{5}$, Hayrunnisa Yesil ${ }^{5}$, Ahmet Yilmaz ${ }^{6}$, Ahmet Var $^{7}$
}

\begin{abstract}
Objective: Diabetes mellitus (DM) is a group of metabolic diseases with high blood glucose, which cause the damage and dysfunction of some of the organ systems. Although various oral drugs are used to treat DM, they do not prevent the development of DM related diseases such as nephropathy and retinopathy and glucose dependent vascular diseases. Thus novel strategies for the prevention and treatment of DM are urgently needed. This research aimed to reveal the effects of Thymus Vulgaris Lamiaceae (TVL) and Thymbra Spicata Lamiaceae (TSL) on the damaging effects of DM.

Methods: Prepared TVL and TSL aqueous extracts were studied in the streptozocin induced experimental diabetic rat model. Blood glucose, body weight, and blood biochemical alterations were measured. Rat kidney for nephropathy were enucleated and fixed in paraffin blocks to examine histopathological changes.

Results: Briefly, impaired blood glucose, and weight loss of Diabetic rats were significantly improved by TVL in dose dependent manner $(\mathrm{P}<0.01)$. Impaired Blood Uric acid, Urea, and liver enzymes were significantly improved and adjusted to the control group values $(P<0.001)$. The histological analyses of the kidney in TVL and TSL groups revealed the findings of significant healing properties, which was similar to the normal structures of kidney.

Conclusions: In this study, strong biochemical, physiological, and histological improvements in the DM related disorders, such as neuropathy and nephropathy were obtained by TVL treatment.
\end{abstract}

Keywords: Diabetes mellitus, Streptozocin, Diabetic rat, Thymus Vulgaris L., Thymbra Spicata L., AST, ALT, UREA, Nephyropathy, Nephyron,

\section{Introduction}

Diabetes mellitus (DM) is the most common metabolic disease referring to hyperglycemia due to the corruption of insulin secretion, insufficient insulin sensitivity, or both. The prevalence of DM continues to increase worldwide, and it predisposes to significantly increased complications. DM can affect almost every organ system in the body, and the level of the damage is particularly related to the severity and duration of the disease $[1,2]$ Type 1 DM (T1D) is an autoimmune disease characterized by the destruction of pancreatic ß-cells. Exposure of environmental harmful substances during neonatal period is accused of leading to initiation of immune process underlying the destruction of $\beta$-cells and the development of disorder [3] Patients with Type 1 Diabetes (T1D) are presented with absolute insulin deficiency, and multiple types of insulin formulations have been developed for the treatment of T1D in the last three decades [4] Type 2 Diabetes (T2D), non-insulin-dependent type of $\mathrm{DM}$, is mainly an adult disease and associated with insulin resistance. The incidences of $\mathrm{T} 2 \mathrm{D}$ rapidly

Received: 15 Aug. 2014, Revised 20 Aug. 2014, Accepted 24 Aug. 2014, Available Online 30 Aug. 2014

${ }^{1}$ Celal Bayar University, School of Medicine, Department of Biophysics, Manisa-Turkey

${ }^{2}$ Yuzuncu Yil University, School of Medicine, Department of Pharmacology, Van-Turkey

${ }^{3}$ Celal Bayar University, School of Medicine, Department of Urology, Manisa-Turkey

${ }^{4}$ Celal Bayar University, School of Medicine, Department of Cardiology, Manisa-Turkey

${ }^{5}$ Celal Bayar University, School of Medicine, Department of Histology, Manisa-Turkey

${ }^{6}$ Dicle University, School of Medicine, Department of Family Medicine, Diyarbakir-Turkey

${ }^{7}$ Celal Bayar University, School of Medicine, Department of Biochemistry, Manisa-Turkey

*Corresponding Author: Zafer Akan E-mail: zafer.akan@cbu.edu.tr 
increase due to the decrease in physical activity, sedentary lifestyle, and aging population. T2D is characterized by insulin insensitivity as a result of insulin resistance, decreased insulin production, and finally pancreatic $\beta$-cell failure. Patients with T2D should receive lifestyle alteration recommendations and diet modification. Pharmacological agents including oral antidiabetics are frequently required. Although novel drugs are being developed, no cure is currently available $[5,6] \mathrm{DM}$ may lead to the microvascular complications, such as nephropathy. Diabetic nephropathy (DN) is characterized by initial microalbuminuria following persistent albuminuria, [7] DN is characterized by distal symmetric polyneuropathy. Thymus vulgaris L. (Local name: Izmir Kekigi) (TVL) is a species of flowering plant in the mint family Lamiaceae and native to the west of Turkey. Thymbra Spicata L (Local name: Karabas Kekik or Zahter) (TSL) is also a member of the Lamiaceae family, and the leaves of this plant have recently gained much popularity as a remedy to combat hypercholesterolaemia [8].

TVL and TSL have been arbitrarily and widely used in the west region of Turkey for the treatment of various diseases, such as diabetes mellitus, diabetes dependent urinary system disorders, in folk medicine. However, no previous scientific report is available regarding the influences of TVL and TSL on DM related damage and impairment in urinary, and blood biochemical systems. Therefore, the present study was created to examine the possible effects of TVL and TSL on the DM associated disorders in some of the organ systems, such as nephropathy, and nephropathy related blood biochemical

\section{Materials and Methods}

\section{Animals and experimental groups}

Male Wistar albino rats weighing $305.2 \pm 4.33 \mathrm{~g}$, 60 days old, were obtained from the Yüzüncü Y1l
University experimental animal unit. Rats were maintained on 12-h dark/light cycle at $22{ }^{\circ} \mathrm{C}$, housed in groups of seven, and fed with a standard commercial rodent chow. The care of the animals and this experimental animal study were conducted with the approval of the Institutional Animal Care and Use Committee of the Yuzuncu Y1l University Experimental Animal Unit and Ethic Committee (YUHADYEK).

\section{DM induction}

To examine the effects of TVL and TSL treatment on DM, fifty six Wistar albino rats were divided into seven equal groups. Group 2, 3, 4, 5, 6 and 7 were induced to DM. Severe DM was induced in the animals by intraperitoneal injection of streptozocin (STZ; Sigma-Aldrich, St. Louis, MO) that was dissolved in $0.1 \mathrm{M}$ citrate buffer solution (0.1 M, pH 4.5) at the dose of $50 \mathrm{mg} / \mathrm{kg}$ body weight (BW). Animals were fasted overnight for 12 $\mathrm{h}$ prior to STZ administration. Water and food were available immediately after dosing. The development of DM was determined by observing hyperglycemia $(>300 \mathrm{mg} / \mathrm{dl})$ as measured by an Accu-Chek Go glucometer (Roche, Mannheim, Germany). Body weights and blood glucose levels were recorded once a week throughout the study. At end of the 5 weeks, Blood samples were collected, and the tissue samples of kidney were enucleated and embedded to paraffin blocks.

\section{Extraction of TVL and TSL:}

The species of TVL and TSL were collected from Aegean region (Aydın and Izmir cities). Taxonomic identification was performed by Associate Prof. Dr. Fevzi Ozgokce. The collected plants were dried in an oven at $40{ }^{\circ} \mathrm{C}$ and then ground into a powder. For extraction, the decoction method and distilled water as solvent were used [8]. For the decoction method, $20 \mathrm{~g}$ of dried powder was extracted with $100 \mathrm{ml}$ of distilled water at $100{ }^{\circ} \mathrm{C}$ for $30 \mathrm{~min}$ in a water bath. 
Subsequently, it was filtered, and the water was evaporated to dryness. The residue was weighed to obtain the extractive yield, and it was in air tight bottle at $4{ }^{\circ} \mathrm{C}$. The yield of dried extract were found \% 5.9 and 5.85, respectively. The extracts were prepared daily. Resolved in 100 and 200 $\mathrm{mg} / \mathrm{ml}$ distilled water and orally administered to the rats daily.

The creation of groups and the assessment of the effects of TVL and TSL treatment on blood glucose level (BGL) and body weight changes:

Diabetic rats were treated by the agents of Glibenclamide, TVL and TSL aqueous extracts. Both BGL and body weight alterations were compared with the result of control group. The groups were created as; (1) no additive; (2) 50 $\mathrm{mg} / \mathrm{kg} \mathrm{STZ}$ only; (3) $50 \mathrm{mg} / \mathrm{kg} \mathrm{STZ}$ plus $5 \mathrm{mg} / \mathrm{kg}$ glibenclamide; (4) $50 \mathrm{mg} / \mathrm{kg} \mathrm{STZ}$ plus $100 \mathrm{mg} / \mathrm{kg}$ TVL; (5) $50 \mathrm{mg} / \mathrm{kg} \mathrm{STZ} \mathrm{plus} 200 \mathrm{mg} / \mathrm{kg}$ TVL; (6) $50 \mathrm{mg} / \mathrm{kg} \mathrm{STZ}$ plus $100 \mathrm{mg} / \mathrm{kg}$ TSL; (7) $50 \mathrm{mg} / \mathrm{kg}$ STZ plus $200 \mathrm{mg} / \mathrm{kg}$ TSL. Body weight and were measured once in a week through 5 weeks. Rats were treated with glibenclamide/TVL/TSL single daily dose.

\section{Blood biochemicals}

The biochemical parameters measured included glucose, urea, uric acid, total cholesterol (TC), triglyceride (TG), aspartate aminotransferase (AST), alanine aminotransferase (ALT), gamma glutamyl transferase (GGT), and creatine kinase (CK). These parameters were measured by using Randox kits (Randox Laboratories Ltd, United Kingdom), and read by spectrophotometry.

\section{Histological assessments}

The samples were fixed in $10 \%$ formalin solution for $48 \mathrm{~h}$. After washing, they were embedded in paraffin using routine embedding procedure. The 5 micron sections were taken from all blocks, and they were stained with hematoxylin-eosin (HE) using routine procedure for histochemical analyses.

\section{Statistical analysis for blood glucose measurements, body weight changes}

One-way Analysis of Variance (ANOVA) and Tukey-Kramer Multiple Comparisons tests were applied to the variables, and each result was reported as mean \pm S.E.M. and $a, p$ value less than 0.05 was accepted as statistically significant. $(* \mathrm{P}<0.05, * * \mathrm{P}<0.01$ and $* * * \mathrm{P}<0.001)$

\section{Statistical analysis for blood parameters}

Descriptive statistics for biochemical parameters; mean, standard deviation (SD), minimum and maximum values were stated. Kruskal-Wallis test were used in order to determine whether there were differences between the determined parameters of groups. The level of statistical significance was taken as $5 \%$, and SPSS 17.0 program was used for the statistical analyses.

\section{Results}

Blood glucose level of the control group was measured in an average of $86.7 \mathrm{mg} / \mathrm{dl}$. BGL were elevated to the average of $422.3 \mathrm{mg} / \mathrm{dl}$ by the single dose STZ $(50 \mathrm{mg} / \mathrm{kg})$ administration. BGL remained stable in both Control and STZ groups for 5 weeks. BGL slightly decreased in Glibenclamide administered group. The most significant results over the increased BGL were obtained with TVL100 mg/kg and TVL $200 \mathrm{mg} / \mathrm{kg}$ treatments $(\mathrm{p}<0.01)$ (Table 1). The mean body weight was $305.2 \mathrm{gr}$, and it was decreased to $208.3 \mathrm{gr}$ by the administration of STZ at the end of 5th week. TVL treatment reduced body weight loss in STZ administrated diabetic rats $(\mathrm{p}<0.01)$ (Table 2$)$. As a result of the biochemical analyses; it was found that almost all of the biochemical parameters were affected by the STZ administration that induced the impaired blood glucose. Particularly the urinary system parameters of urea, uric acid, and liver 
Table 1: The effects of different doses of aqueous extract of TVL and TSL on fasting blood glucose level (mg/dl) in streptozocin induced diabetic rats. Values given represent the mean $\pm \mathrm{SD}$; One-way Analysis of Variance (ANOVA) was applied to results $* \mathrm{P}<0.05$, $* * \mathrm{P}<0.01$ and $* * * \mathrm{P}<0.001$.

\begin{tabular}{|c|c|c|c|c|c|}
\hline & \multicolumn{5}{|c|}{ Blood glucose (mg/dl) } \\
\hline & $1^{\text {st }}$ week & $2^{\text {nd }}$ week & $3^{\text {rd }}$ week & $4^{\text {th }}$ week & $5^{\text {th }}$ week \\
\hline CRs & $86,70 \pm 10,82$ & $94,40 \pm 14,72$ & $94,70 \pm 14,11$ & $96,00 \pm 16,81$ & $94,80 \pm 11,22$ \\
\hline DRs & $425,22 \pm 133,01$ & $409,56 \pm 80,43$ & $423,67 \pm 108,99$ & $436,43 \pm 68,62$ & $416,63 \pm 110,64$ \\
\hline $\mathrm{DRs}+\mathrm{Gli}$ & $340,50 \pm 89,37$ & $410,00 \pm 118,89$ & $341,00 \pm 107,59$ & $332,33 \pm 191,85$ & $345,11 \pm 140,73$ \\
\hline DRs+TVL100 & $312,10 \pm 53,71$ & $286,11 \pm 66,04$ & $298,78 \pm 85,85$ & $237,56 \pm 100,37$ & $322,75 \pm 182,56$ \\
\hline DRs+TVL200 & $299,10 \pm 83,55$ & $293,70 \pm 52,23$ & $278,40 \pm 118,16$ & $288,40 \pm 116,48$ & $261,67 \pm 144,76$ \\
\hline DRs+TSL100 & $303,50 \pm 76,57$ & $431,40 \pm 91,14$ & $367,00 \pm 140,82$ & $345,50 \pm 115,92$ & $425,33 \pm 156,48$ \\
\hline DRs+TSL200 & $406,80 \pm 81,68$ & $395,89 \pm 110,72$ & $355,22 \pm 113,39$ & $359,88 \pm 166,87$ & $348,25 \pm 143,99$ \\
\hline CRs/versus & & & P value & & \\
\hline DRs & $* * *$ & $* * *$ & $* * *$ & $* * *$ & $* * *$ \\
\hline $\mathrm{DRs}+\mathrm{Gli}$ & $* * *$ & $* * *$ & $* * *$ & $* *$ & $* *$ \\
\hline DRs+TVL100 & $* * *$ & $* * *$ & $* *$ & $*$ & $*$ \\
\hline DRs+TVL200 & $* * *$ & $* * *$ & $* *$ & $\mathrm{P}>0.05$ & $\mathrm{P}>\mathbf{0 . 0 5}$ \\
\hline DRs+TSL100 & $* * *$ & $* * *$ & $* * *$ & $* * *$ & $* * *$ \\
\hline DRs+TSL200 & $* * *$ & $* * *$ & $* * *$ & $* * *$ & $* *$ \\
\hline
\end{tabular}

Table 2: Effects of different doses of aqueous extract of TVL and TSL on body weight ( $\mathrm{g}$ ) changes of streptozocin induced diabetic rats. Values given represent the mean $\pm \mathrm{SD}$; One-way Analysis of Variance (ANOVA) was applied to results. ${ }^{*} \mathrm{P}<0.05 * * \mathrm{P}<0.01$ and $* * * \mathrm{P}<0.001$

\begin{tabular}{|c|c|c|c|c|c|}
\hline \multirow[b]{3}{*}{ CRs } & \multicolumn{5}{|c|}{ Body weight (in g) } \\
\hline & $1^{\text {st }}$ week & $2^{\text {nd }}$ week & $3^{\text {rd }}$ week & $4^{\text {th }}$ week & $5^{\text {th }}$ week \\
\hline & $296,50 \pm 30,28$ & $299,00 \pm 27,67$ & $302,50 \pm 27,00$ & $308,00 \pm 25,73$ & 718 \\
\hline DRs & $261,22 \pm 34,65$ & $231,11 \pm 35,07$ & $226,11 \pm 33,61$ & $208,33 \pm 36,66$ & $19556 \pm 2910$ \\
\hline DRs+Gli & $272,00 \pm 24,40$ & $263,50 \pm 26,46$ & $259,00 \pm 40,33$ & $243,00 \pm 37,51$ & $235,50 \pm 53,51$ \\
\hline DRs+TVL100 & $259,00 \pm 17,29$ & $251,22 \pm 30,80$ & $247,22 \pm 34,01$ & $247,78 \pm 30,83$ & $246,67 \pm 42,43$ \\
\hline DRs+TVL200 & $274,50 \pm 12,57$ & $259,10 \pm 26,55$ & $244,00 \pm 40,61$ & $253,50 \pm 40,83$ & $265,50 \pm 43,11$ \\
\hline DRs+TSL100 & $266,00 \pm 14,49$ & $241,00 \pm 29,61$ & $228,50 \pm 34,56$ & $211,50 \pm 44,91$ & $206,11 \pm 52,49$ \\
\hline DRs+TSL200 & $277,00 \pm 21,11$ & $256,67 \pm 19,36$ & $258,89 \pm 37,48$ & $248,33 \pm 41,16$ & $251,11 \pm 50,17$ \\
\hline CRs/versus & & & $\mathrm{P}$ value & & \\
\hline DRs & $P>0.05$ & $* * *$ & $* * *$ & $* * *$ & $* * *$ \\
\hline $\mathrm{DRs}+\mathrm{Gli}$ & $P>0.05$ & $P>0.05$ & $P>0.05$ & $* *$ & $* * *$ \\
\hline DRs+TVL100 & $P>0.05$ & $* *$ & $*$ & $*$ & $* *$ \\
\hline DRs+TVL200 & $P>0.05$ & $*$ & $* *$ & $*$ & $P>0.05$ \\
\hline DRs+TSL100 & $P>0.05$ & $* * *$ & $* * *$ & $* * *$ & $* * *$ \\
\hline $\mathrm{DRs}+\mathrm{TSL} 200$ & $P>0.05$ & $* *$ & $\mathrm{P}>0.05$ & $*$ & $*$ \\
\hline
\end{tabular}

enzymes including ALT, AS, and GGT were disrupted after the induction of DM by the STZ administration.

Although some of the biochemical parameters were affected by the glibenclamide treatment, most of the parameters were resistant to the glibenclamide treatment $(p<0.01) \quad$ (Figure 1, Table 3). The measured values of the blood glucose in STZ induced diabetic rats were significantly higher than in the control. The glucose levels were significantly declined by TVL100 and TVL200 mg/kg treatments as compared with just STZ and control groups. Some alterations in the enzymatic activities were also determined. The increased ALT level subsequent to the STZ administration was reduced by TVL100 and TVL200 mg/kg, and the reduction 
was more distinct by the administration of TVL 200 $\mathrm{mg} / \mathrm{kg}$. The AST and GGT readings were also reduced by the presence of TVL $(\mathrm{p}<0.01)$ (Figure 1, Table 3). was treated by TVL $200 \mathrm{mg} / \mathrm{kg}$. Therefore, we concluded that TVL $200 \mathrm{mg} / \mathrm{kg}$ provided more posivitive impacts on the damaging effects of DM on the structure of glomerules (Table 4).

Table 3. The effects of TVL and TSL on the blood biochemical parameters and electrolyte concentrations of diabetic rats. Descriptive statistics of the studied variables. Values given represent the mean and S.E.M.

\begin{tabular}{|c|c|c|c|c|c|c|c|c|}
\hline & CRs & DRs & $\begin{array}{c}\text { DRs } \\
\text { Gli }\end{array}$ & $\begin{array}{c}\text { DRs } \\
\text { TVL100 }\end{array}$ & $\begin{array}{c}\text { DRs } \\
\text { TVL200 }\end{array}$ & $\begin{array}{c}\text { DRs } \\
\text { TSL100 }\end{array}$ & $\begin{array}{c}\text { DRs } \\
\text { TSL200 }\end{array}$ & $\mathbf{p}$ \\
\hline GLU & $167,0 \pm 36,2 \mathrm{c}$ & $419,0 \pm 165,3 \mathrm{ab}$ & $513,5 \pm 107,9 a$ & $464,6 \pm 218,2 \mathrm{a}$ & $277,0 \pm 140,1 b c$ & $573,8 \pm 47,5 a$ & $479,3 \pm 167,5 a$ & 0,001 \\
\hline URE & $33,5 \pm 5,5 \mathrm{~d}$ & $75,0 \pm 30,4 a b$ & $84,4 \pm 19,8 \mathrm{a}$ & $50,3 \pm 15,1 d$ & $53,8 \pm 26,9 \mathrm{bcd}$ & $63,2 \pm 11,5 \mathrm{abc}$ & $58,7 \pm 16,3 \mathrm{bc}$ & 0,003 \\
\hline KOL & $60,5 \pm 12,6$ & $61,1 \pm 11,4$ & $67,4 \pm 12,6$ & $70 \pm 13$ & $71,5 \pm 12,6$ & $72,4 \pm 10,5$ & $59,4 \pm 10,8$ & 0,200 \\
\hline TG & $110,3 \pm 44,2 \mathrm{a}$ & $50,5 \pm 5,7 \mathrm{~b}$ & $70,7 \pm 17,9 b$ & $68,9 \pm 18,3 b$ & $73,3 \pm 17,5 b$ & $118,6 \pm 31,4 a$ & $60,0 \pm 15,4 b$ & 0,000 \\
\hline HDL & $21,5 \pm 6,3$ & $24,4 \pm 5,9$ & $27,3 \pm 5,4$ & $26,8 \pm 6,1$ & $24,8 \pm 5,9$ & $30,4 \pm 5$ & $24 \pm 4,8$ & 0,110 \\
\hline LDL & $8,2 \pm 2,2$ & $7,8 \pm 1,8$ & $9 \pm 2,3$ & $9,9 \pm 2,7$ & $9,7 \pm 1,4$ & $10,2 \pm 1,8$ & $7,7 \pm 1,4$ & 0,138 \\
\hline AST & $125,8 \pm 64,1 b$ & $445,4 \pm 217,3 b$ & $978,8 \pm 660,8 \mathrm{a}$ & $344,4 \pm 316,8 b$ & $173,5 \pm 94,2 b$ & $485,0 \pm 312,6 b$ & $332,0 \pm 320,2 b$ & 0,001 \\
\hline ALT & $36,7 \pm 4,9 \mathrm{c}$ & $164,8 \pm 98,4 b c$ & $375,9 \pm 225,9 a$ & $148,4 \pm 138,5 b c$ & $58,3 \pm 55,9 c$ & $237,8 \pm 129,1 \mathrm{ab}$ & $140,1 \pm 123,5 b c$ & 0,001 \\
\hline GGT & $-, 3 \pm 0,8 \mathrm{c}$ & $6,5 \pm 5,8 \mathrm{ab}$ & $8,4 \pm 5,8 \mathrm{a}$ & $3,9 \pm 4,5 \mathrm{abc}$ & $-, 2 \pm 1,3 c$ & $8,0 \pm 5,1 \mathrm{a}$ & $2,6 \pm 3,9 b c$ & 0,005 \\
\hline ALB & $3 \pm 0,2$ & $2,8 \pm 0,3$ & $2,8 \pm 0,3$ & $2,8 \pm 0,2$ & $2,9 \pm 0,2$ & $2,6 \pm 0,3$ & $2,9 \pm 0,2$ & 0,566 \\
\hline FT3 & $1,8 \pm 0,1 \mathrm{a}$ & $1,3 \pm 0,1 \mathrm{ab}$ & $1,4 \pm 0,1 \mathrm{ab}$ & $1,8 \pm 0,6 \mathrm{a}$ & $1,8 \pm 0,2 \mathrm{a}$ & $1,2 \pm 0,3 b$ & $1,7 \pm 0,3 \mathrm{ab}$ & 0,035 \\
\hline FT4 & $1,3 \pm 0,2 \mathrm{a}$ & $, 8 \pm 0,1 \mathrm{c}$ & $, 9 \pm 0,1 \mathrm{bc}$ & $1,1 \pm 0,3 \mathrm{abc}$ & $1,3 \pm 0,2 \mathrm{ab}$ & $, 8 \pm 0,2 \mathrm{c}$ & $1,1 \pm 0,3 \mathrm{abc}$ & 0,044 \\
\hline $\mathbf{C a}$ & $9,5 \pm 0,2 \mathrm{bc}$ & $9,4 \pm 0,5 \mathrm{c}$ & $9,9 \pm 0,5 \mathrm{abc}$ & $10,1 \pm 0,7 \mathrm{ab}$ & $9,6 \pm 0,1 b c$ & $10,3 \pm 0,5 \mathrm{a}$ & $9,8 \pm 0,5 \mathrm{abc}$ & 0,036 \\
\hline Mg & $1,9 \pm 0,2$ & $4,6 \pm 7$ & $2,5 \pm 0,5$ & $2,4 \pm 0,6$ & $2 \pm 0,1$ & $2,6 \pm 0,3$ & $2,1 \pm 0,3$ & 0,001 \\
\hline $\mathbf{N a}$ & $137,7 \pm 1,5 \mathrm{ab}$ & $135,3 \pm 5,1 \mathrm{ab}$ & $142,4 \pm 4,7 \mathrm{a}$ & $141,0 \pm 4,3 \mathrm{ab}$ & $136,7 \pm 3,6 \mathrm{ab}$ & $140,2 \pm 1,5 \mathrm{ab}$ & $122,3 \pm 39,5 b$ & 0,033 \\
\hline $\mathrm{Cl}$ & $101,8 \pm 1,7 \mathrm{a}$ & $97,1 \pm 6,6 \mathrm{bc}$ & $99,2 \pm 2,5 \mathrm{ab}$ & $97,8 \pm 3,8 \mathrm{abc}$ & $97,2 \pm 3,5 \mathrm{bc}$ & $94,0 \pm 1,6 \mathrm{c}$ & $94,7 \pm 3,4 \mathrm{bc}$ & 0,010 \\
\hline
\end{tabular}

As to histological cross sections, kidney structure was detected normally with normal glomerules surrounded by Bowman's capsule, proximal and distal convoluted tubules, and collecting tubules were observed in normal morphological properties in the control group. In STZ group without any treatment, the degenerated glomerules that was infiltrated by the inflammatory cells were detected. In addition, the basement membrane of glomerule in STZ group was slightly thicker than in the control group. Edematous changes in the proximal convoluted tubules were also detected. The histological properties of kidney in group $3,4,5,6$ and 7 revealed the features of healing such as normal structure of the glomerule, less inflammatory cell infiltration, and less edematous changes of the convoluted tubules. However, the absence of inflammatory cells, normal basement membrane thickness, and non-edematous structure of convoluted tubules were observed in group 5 that

\section{Discussion}

DM contains a group of metabolic diseases, and it is characterized by the increase of blood glucose as a result of the disorders in insulin secretion, insulin action, or both. The prolonged exposure of the organ systems to hyperglycemia is resulted with the damage, dysfunction, and failure of different organs, such as kidneys, blood vessels, and nerves [9] TVL and TSL are known with their antimicrobial and antiviral effects, thus the use is common among the population for the treatment of DM and various diseases. They are characterized by the large scale component of free radical scavenger essential oils such as thymol, carvacrol, 8terpinene, $\mathrm{p}$-ceymene and $\alpha$-pinene. In addition, the chemical compositions of TVL and TSL essential oils varies in a wide range. Carvacrol and thymol are the main components of the mint family Lamiaceae plants. The rate of these components is 
due to the environment and ecology [8] The aim of the present study was to analyze the impact of TVL and TSL in terms of blood glucose, vascular, renal and cognitive systems in diabetic rats. Streptozotocin is particularly toxic to the insulinproducing beta cells of the pancreas in mammals. It is used in medical research to produce an animal model for Type $1 \mathrm{DM}$ in single large dose as well as Type $2 \mathrm{DM}$ with multiple low doses. In a long period of time, diabetic rats are characterized by high blood glucose and body weight loss. In our study, we produced Type 1 DM by a single large dose of STZ administration $(50 \mathrm{mg} / \mathrm{kg})$ in the wistar albino rats. The diabetic rats were treated by glibenclamide, TVL and TSL aqueous extracts. It was seen that TVL was significantly effective in the avoidence of the increase in blood glucose, weight loss, the decline in cognitive functions, and also in the improvement of them.

In clinical practice, the more commonly used liver function tests (LFTs) including the serum aminotransferases, alkaline phosphatase, bilirubin, albumin, and prothrombin time are commonly used for screening for liver disease, monitoring the progression of the disease, and reflect the damaging effects of hepatotoxic drugs. Alanine aminotransferase (ALT) and aspartate aminotransferase (AST) are called as aminotransferases, the level of them in the blood increase as a result of hepatocyte injury. Thus, they are commonly used as a marker reflecting hepatic disorder. The patients with type 2 DM have a higher incidence of the abnormalities in liver function tests than the normal one. Antidiabetic agents have generally been shown to decrease alanine aminotransferase levels as tighter blood glucose levels are achieved [10] In our study, the greatest improvement in hepatic enzymes was significantly seen in TVL group. These enzymes much more decreased in TVL group than in the other groups. Therefore, it was supposed that TVL might provide the protecting effect against the toxic effects of DM and DM related hepatic dysfunction by providing the regulation of blood glucose level. In addition to the biochemical analysis, the histological sections of rat aorta were examined in terms of macrovascular complications. DM has multisystemic damaging effects, thus diabetic nepropathy (DN) is one of the most severe complications of DM and has become the most common major cause of end-stage renal disease (ESRD) in the United States and Europe [11] DN is commonly defined as an increase in urinary albumin excretion and detoriorated renal function as diagnosed by as abnormal plasma creatinine level [12] The pathogenesis of DN is complex and is not clearly defined yet. Thus, many researchers investigate the pathogenesis of $\mathrm{DN}$ and the prevention, as well as, the cure [13] Glucose and its metabolites activate protein kinase $\mathrm{C}$, the polyol pathway and non-enzymatic glycation, and these pathways cause the occurrence of renal functional and structural changes [14] Therefore, hyperglycemia has the primary role in the cascade of the damage mediated by cytokines that produces oxidative stress, abnormal glycosylation, lipid peroxidation, and the production of further inflammatory elements [15] There were increasing findings stated that immunologic and inflammatory mechanisms play important roles in the development and progression of DN [16] Inflammatory cytokines including IL-1, IL-6, IL18, TNF- $\alpha$, TGF- $\beta$, and MCP-1 have been determined as a part of the pathophysiological processes of DN [17] Some alterations in blood pressure and hemodynamics are superimposed to these mechanisms [18] The hemodynamic changes including glomerular hyperperfusion and hyperfiltration become evident before the appearance of earliest measurable clinical signs of nephropathy [15]. 
Table 4: Histological section of kidney tissue taken with microscope. Hematoxylin and Eosin (H\&E) Stain. CRs: Control Rats DRs: Diabetic Rats, STZ $50 \mathrm{mg} / \mathrm{kg}$, Glibenclamid $5 \mathrm{mg} / \mathrm{kg}$

Groups

$1 \mathrm{CRs}$

2 DRs

3 DRs+Glibenclamid

4 DRs+TVL 100mg/kg

$5 \mathrm{DRs}+\mathrm{TVL} 200 \mathrm{mg} / \mathrm{kg}$

6 DRs+TSL 100mg/kg

7 DRs+TSL 200mg/kg
Kidney x100
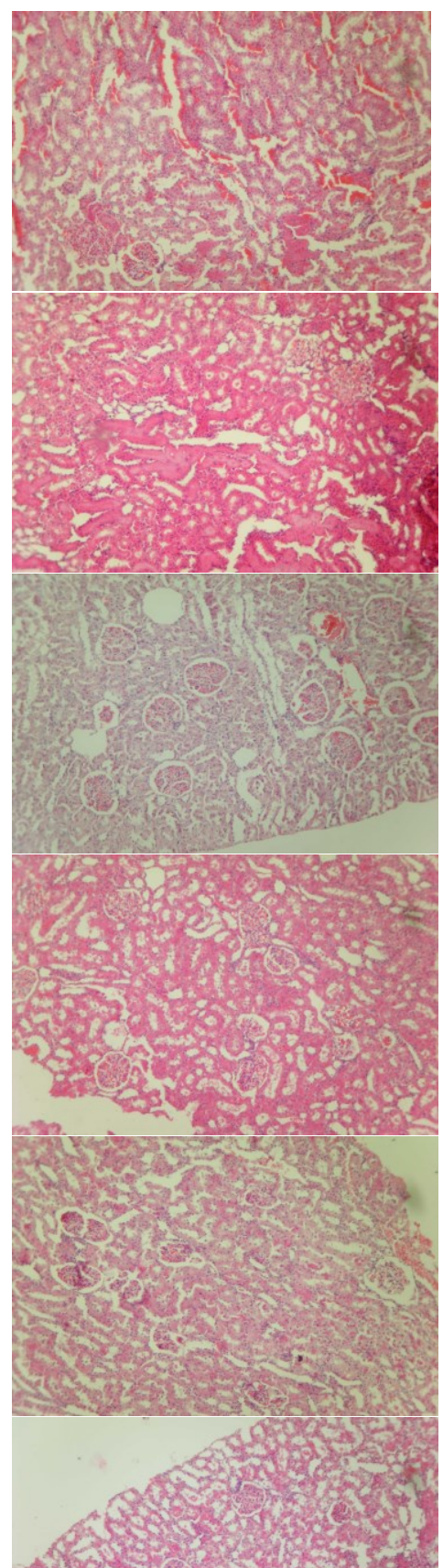

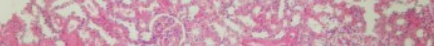

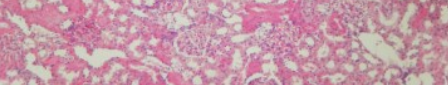

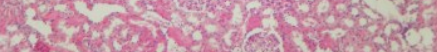

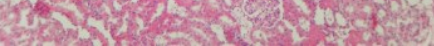

$\sqrt{30}+3$
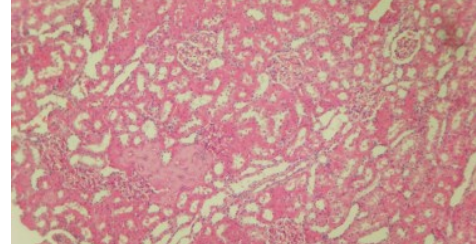

Kidney x400

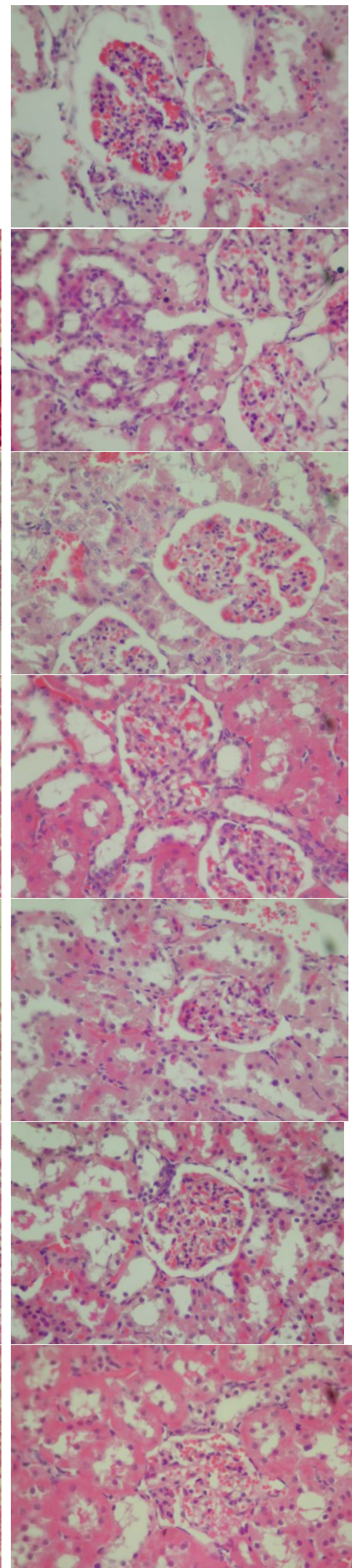


Increased blood glucose levels, deteriorated hemodynamics, immunological and inflammatory reactions, and injury of the glomerular basement membrane and podocytes create the pathophysiological basis of DN related renal dysfunction [19]

The earliest renal manifestation of DM is glomerular hyperfiltration that results from functional changes in the nephron at the level of the glomerulus [20] Subsequently, thickening of the glomerular basement membrane, glomerular hypertrophy and mesangial expansion is occurred [21] When we particularly look at the primary hystopathological alterations in kidney with $\mathrm{DN}$, it is seen that $\mathrm{DN}$ related renal damage is characterized by some alterations in glomerular permeability and structure. Normally, the glomerular wall contains three layers: endothelial cells, basement membrane, and epithelial cells (podocytes). The selectivity of glomerular filtration is commonly provided by the basement membrane where the filtration barrier excludes proteins on the basis of their size and charge [22] However, the damage of the permeability barrier cause to proteinuria in DN [23] The structural damage of diabetic nephropathy in kidney include the accumulation of mesangial matrix and thickening of the basement membrane in the glomeruli, tubular hypertrophy and associated alterations in the tubulointerstitium with tubolointerstitial fibrosis [24] These abnormalities are associated with the renal overproduction of extracellular matrix proteins [25] In our study, we histologically analyzed the possible alterations associated with kidney in 7 groups to determine the possible impact of TVL treatment on the damaging effects of DN. The histological analysis of renal tissues revealed that kidney structures with normal morphological properties in group 1 replaced with degenerated glomerules that were infiltrated with inflammatory cells, slightly thickened glomerular basement membrane, and proximal convoluted tubules with edematous changes in group 2. It was seen that STZ created significant damages in the structure of kidney. Nevertheless, in the group of 3, 4, 5, 6, and 7, while different agents with various doses were applied to improve the damages of STZ exposure, the subsequent histological analyses revealed that the significant findings of healing including normal structure of glomerule, less inflammatory cells infiltration, and less edematous changes of convoluted tubules were determined. In addition, more improvements including the absence of inflammatory cells, normal basement membrane thickness, and non-edematous structure of convoluted tubule were particularly observed in group 5. Therefore, it was concluded that TVL 200 $\mathrm{mg} / \mathrm{kg}$ provided more positive impacts on the damaging effects of DM on the structure of glomerules.

In conclusion, it was supposed that both TVL and TSL had protecting and healing effects against the damaging effects of DM in terms of blood glucose, renal and liver enzyme systems in diabetic rats. However, it was also determined that TVL 200 $\mathrm{mg} / \mathrm{kg}$ could provide the greatest improvement in these terms, thus it should be preferred as an effective and alternative treatment modality in DM related disorders. These findings should be investigated by new comprehensive studies.

Acknowledgements: This project was supported by Yüzüncü yıl University Scientific Research Project Funding (YYU-BAP/2013-SBE-YL051). Thanks to Associate Prof. Dr. Fevzi Özgökçe for herbal taxonomy and Associate Prof. Dr. Siddik Keskin for statistical analysis.

Conflict of Interest: The authors declared that they had no conflicts of interest. 


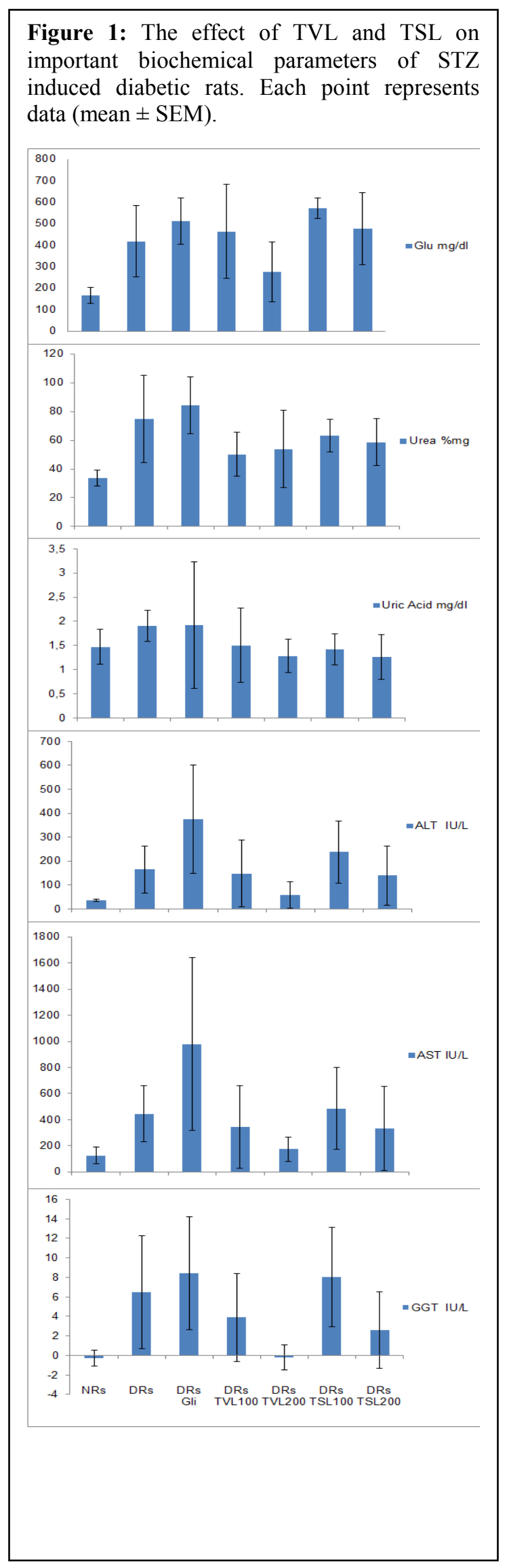

\section{References}

1. Rehman HU, Mohammed K. Perioperative management of diabetic patients. Current surgery. 2003;60(6):607-11.

2. Krishnan B, Babu S, Walker J, Walker AB, Pappachan JM. Gastrointestinal complications of diabetes mellitus. World journal of diabetes. 2013;4(3):51-63.

3. Majeed AA, Mea, Hassan K. Risk Factors for Type 1 Diabetes Mellitus among Children and Adolescents in Basrah. Oman medical journal. 2011;26(3):189-95.

4. Chen W, Xie A, Chan L. Mechanistic basis of immunotherapies for type 1 diabetes mellitus. Translational research : the journal of laboratory and clinical medicine. 2013;161(4):217-29.

5. Olokoba AB, Obateru OA, Olokoba LB. Type 2 diabetes mellitus: a review of current trends. Oman medical journal. 2012;27(4):269-73.

6. Germino FW. Noninsulin treatment of type 2 diabetes mellitus in geriatric patients: a review. Clinical therapeutics. 2011;33(12):1868-82

7. Gross JL, de Azevedo MJ, Silveiro SP, Canani LH, Caramori ML, Zelmanovitz T. Diabetic nephropathy: diagnosis, prevention, and treatment. Diabetes care. 2005;28(1):164-76.

8. Akkol EK, Avci G, Kucukkurt I, Keles H, Tamer U, Ince $\mathrm{S}$, et al. Cholesterol-reducer, antioxidant and liver protective effects of Thymbra spicata L. var. spicata. Journal of ethnopharmacology. 2009;126(2):314-9.

9. American Diabetes A. Diagnosis and classification of diabetes mellitus. Diabetes care. 2010;36:67-74

10. Harris EH. Elevated Liver Function Tests in Type 2 Diabetes. Clinical Diabetes. 2005;3:115-119.

11. Molitch ME, DeFronzo RA, Franz MJ, Keane WF, Mogensen CE, Parving $\mathrm{HH}$, et al. Nephropathy in diabetes. Diabetes care. 2004;27 Suppl 1:S79-83.

12. Yang W, Lu J, Weng J, Jia W, Ji L, Xiao J, et al. Prevalence of diabetes among men and women in China. The New England journal of medicine. 2010;362(12):1090-101.

13. Wada J, Makino H. Historical chronology of basic and clinical research in diabetic nephropathy and contributions of Japanese scientists. Clinical and experimental nephrology. 2009;13(5):405-14.

14. Jerums G, Premaratne E, Panagiotopoulos S, Clarke S, Power DA, MacIsaac RJ. New and old markers of progression of diabetic nephropathy. Diabetes research and clinical practice. 2008;82 Suppl 1:S30-7.

15. Dronavalli S, Duka I, Bakris GL. The pathogenesis of diabetic nephropathy. Nature clinical practice Endocrinology \& metabolism. 2008;4(8):444-52.

16. Navarro-Gonzalez JF, Mora-Fernandez C. The role of inflammatory cytokines in diabetic nephropathy. Journal of the American Society of Nephrology : JASN. 2008;19(3):433-42.

17. Kanasaki K, Taduri G, Koya D. Diabetic nephropathy: the role of inflammation in fibroblast activation and kidney fibrosis. Frontiers in endocrinology. 2013;4:7. 
18. Meguro S, Shigihara T, Kabeya Y, Tomita M, Atsumi Y. Increased risk of renal deterioration associated with low eGFR in type 2 diabetes mellitus only in albuminuric subjects. Internal medicine. 2009;48(9):657-63.

19. Zhu WW, Chen HP, Ge YC, Xie HL, Zeng CH, Li LS, et al. Ultrastructural changes in the glomerular filtration barrier and occurrence of proteinuria in Chinese patients with type 2 diabetic nephropathy. Diabetes research and clinical practice. 2009;86(3):199-207.

20. Abdel-Rahman EM, Saadulla L, Reeves WB, Awad AS. Therapeutic modalities in diabetic nephropathy: standard and emerging approaches. Journal of general internal medicine. 2012;27(4):458-68.

21. Reddy MA, Tak Park J, Natarajan R. Epigenetic modifications in the pathogenesis of diabetic nephropathy. Seminars in nephrology. 2013;33(4):341-53.

22. Brenner BM, Hostetter TH, Humes HD. Glomerular permselectivity: barrier function based on discrimination of molecular size and charge. The American journal of physiology. 1978;234(6):F455-60.

23. Varghese SA, Powell TB, Budisavljevic MN, Oates JC, Raymond JR, Almeida JS, et al. Urine biomarkers predict the cause of glomerular disease. Journal of the American Society of Nephrology : JASN. 2007;18(3):913-22.

24. Najafian B, Mauer M. Progression of diabetic nephropathy in type 1 diabetic patients. Diabetes research and clinical practice. 2009;83(1):1-8.

25. Suzuki D, Miyazaki M, Jinde K, Koji T, Yagame M, Endoh M, et al. In situ hybridization studies of matrix metalloproteinase-3, tissue inhibitor of metalloproteinase1 and type IV collagen in diabetic nephropathy. Kidney international. 1997;52(1):111-9.

Copyright $(\mathcal{C} 2014$ The Author(s); This is an open-access article distributed under the terms of the Creative Commons Attribution License (http://creativecommons.org/licenses/by/4.0), which permits unrestricted use, distribution, and reproduction in any medium, provided the original work is properly cited. 